\title{
Bovine lactoferrin reduces plasma triacylglycerol and NEFA accompanied by decreased hepatic cholesterol and triacylglycerol contents in rodents
}

\author{
Takashi Takeuchi ${ }^{1}$, Hirohiko Shimizu ${ }^{2}$, Kunio Ando ${ }^{2}$ and Etsumori Harada ${ }^{1 *}$ \\ ${ }^{1}$ Department of Veterinary Physiology, Faculty of Agriculture, Tottori University, Tottori 680-0945, Japan \\ ${ }^{2}$ NRL Pharma. Inc., Kawasaki, Kanagawa 213-0012, Japan
}

(Received 17 September 2003 - Revised 16 December 2003 - Accepted 18 December 2003)

In the present study we examined whether oral administration of bovine lactoferrin (bLF) reduces plasma or hepatic triacylglycerol and cholesterol in mice. When bLF mixed with a standard commercial diet $(10 \mathrm{~g} / \mathrm{kg})$ was given to mice for 4 weeks, plasma triacylglycerol and NEFA decreased, while plasma HDL-cholesterol levels increased $(P<0 \cdot 01)$. These changes in plasma lipid profiles were accompanied by significant decreases in hepatic cholesterol and triacylglycerol contents. When mice were fed a high-fat diet containing $300 \cdot 0 \mathrm{~g}$ lard, $10 \cdot 0 \mathrm{~g}$ cholesterol and $2.5 \mathrm{~g}$ bovine bile powder/kg for 4 weeks, bovine LF did not have any significant effects on plasma or hepatic cholesterol and triacylglycerol concentrations. Furthermore, bLF had no significant effects on faecal excretion of total bile acids in mice. Interestingly, bLF showed a suppressive effect on the lymphatic triacylglycerol absorption in chronically treated rats. We conclude that bLF has a beneficial effect on plasma cholesterol levels and retards hepatic lipid accumulation in mice fed a standard diet.

Lactoferrin: Triacylglycerol: Hypercholesterolaemia: Cholesterol accumulation

Lactoferrin is an $80 \mathrm{kDa}$ non-haem-Fe-binding, single-chain, multifunctional glycoprotein, consisting of two lobes, each of which binds a ferric ion. Virtually all body fluids contain lactoferrin, but it is especially abundant in milk. In particular, large quantities are found in the colostrum of such diverse species as man, bovine animals, rhesus monkeys, mice and sows (Masson et al. 1996). In addition, polymorphonuclear leucocytes produce lactoferrin and store it in lactoferrin granules as maturation proceeds. A number of physiological roles have been proposed for lactoferrin, including anti-inflammatory, immunomodulatory, antimicrobial, antiviral and anticarcinogenic functions (Brock, 2002). Thus, lactoferrin is regarded as a host-defence mediator. Furthermore, several lines of evidence have demonstrated the occurrence of specific lactoferrin receptors in a variety of cells, such as leucocytes (van Snick \& Masson, 1976), lymphocytes (Bennett \& Davis, 1981), hepatocytes (Debanne et al. 1985; Gijsbertus et al. 1999) and endothelial cells (Fillebeen et al. 1999). Recently Hayashida et al. (2003) reported that bovine lactoferrin (bLF) possessed remarkable anti-nociceptive activity in the rat spinal cord. Although lactoferrin receptors are thought to be involved in mediating these multifunctional activities, their physiological functions are still obscure.

Our attention has been focused on the effect of lactoferrin on lipid metabolism, because dyslipidaemia plays a crucial role in both the onset and progression of CHD. It was reported that ingestion of protein from milk especially affects plasma lipid levels, and whey protein also tends to lower plasma lipid levels (Zhang \& Beynen, 1993). Recently, it was shown that lactoferrin in liver cells could bind to LDL receptor-related protein in the blood (Huettinger et al. 1988; Ziere et al. 1992). Intravenous injection of large amounts of lactoferrin inhibited the LDL receptor-related protein-mediated uptake of ApoEcontaining lipoproteins such as chylomicron remnants and VLDL (Huettinger et al. 1988; Crawford \& Borensztajn, 1999). It has been suggested that amino acid sequences rich in basic amino acids near the N-terminus of lactoferrin, and resembling the LDL receptor-related protein-binding sequence in ApoE, compete with ApoE in their attempts to bind to LDL receptor-related protein (Huettinger et al. 1988; Crawford \& Borensztajn, 1999). Kajikawa et al. (1994) reported that lactoferrin might compete with the scavenger receptor of macrophages for binding to modify LDL. This would resemble the cases of lactoferrin, LDL receptor-related protein and ApoE mentioned earlier.

In the present study we investigated the effects of bLF on lipid metabolism in mice given either a commercial diet or a high-fat diet containing fat, cholesterol and bile acid. Furthermore, we examined what may be the 
mechanism by which bLF suppresses plasma or hepatic cholesterol and triacylglycerol and thereby improves lipid metabolism.

\section{Materials and methods}

\section{Diets}

The diet in Expt 1 was a commercial diet powder (CE-2; Nihon CLEA, Tokyo, Japan). bLF was purchased from Tatua Biologics (Tatua, New Zealand). bLF was mixed at a concentration of $10 \mathrm{~g} / \mathrm{kg}$ standard commercial diet.

The diet in Expt 2 was based on the AIN 76A purified rodent diet (Hokanson \& Austin, 1996; Jeppesen et al. 1998). Table 1 shows the composition of each diet, including the basal group, the basal + bLF group, the high-fat (HF) group, and the $\mathrm{HF}+\mathrm{bLF}$ group for Expt 2. The all four diets had equal amounts of casein. Both cholesterol (Nacalai Tesque, Tokyo, Japan) and gall extract powder (Wako Pure Chemical, Osaka, Japan) were substituted for an equal weight of sucrose. In HF diets, lard was increased to $300 \mathrm{~g} / \mathrm{kg}$ by reducing sucrose $(-150 \mathrm{~g} / \mathrm{kg})$ and maize starch $(-150 \mathrm{~g} / \mathrm{kg})$. bLF was mixed at a concentration of $10 \mathrm{~g} / \mathrm{kg}$ with the basal and HF diets.

\section{Animals}

Male ICR strain mice, 5 weeks old, were purchased from Tokyo Experimental Animal Co., Ltd (Tokyo, Japan). Wistar-Imamichi strain male rats, 5 weeks old, were obtained from the Institute of Animal Reproduction (Ibaragi, Japan). The animals were housed in an air-conditioned room at $22 \pm 2^{\circ} \mathrm{C}$ with a $12 \mathrm{~h}$ light-dark cycle (lights on 07.00 hours). The animals first were fed a commercial diet (CE-2; Nihon CLEA) for 1 week while they became acclimated to the environment. In the Expts 1 and 2, the mice were then fed one of the test diets for 4 weeks with free access to food and water. Body weight and food intake were determined at $3 \mathrm{~d}$ intervals.

On day 28 the mice were fasted overnight and the next day were anaesthetized with pentobarbital sodium

Table 1. Dietary composition of test meal in Expt $2(\mathrm{~g} / \mathrm{kg})$

\begin{tabular}{lcccc}
\hline & \multicolumn{4}{c}{ Diet } \\
\cline { 2 - 5 } Ingredient & Basal & Basal + bLF & HF & HF + bLF \\
\hline Casein & 250 & 250 & 250 & 250 \\
Maize starch & 417.5 & 407.5 & 217.5 & 207.5 \\
Sucrose & 250 & 250 & 150 & 150 \\
Lard & 0 & 0 & 300 & 300 \\
bLF* & 0 & 10 & 0 & 10 \\
Mineral mix $†$ & 40 & 40 & 40 & 40 \\
Vitamin mix $†$ & 10 & 10 & 10 & 10 \\
Cellulose & 20 & 20 & 20 & 20 \\
Cholesterolł & 10 & 10 & 10 & 10 \\
Bovine bile powder§ & 2.5 & 2.5 & 2.5 & 2.5 \\
\hline
\end{tabular}

bLF, bovine lactoferrin; HF, high fat.

* Tatua Biologics, Tatua, New Zealand.

†The composition of mineral and vitamin mixtures has been described by Kohashi et al. (1990).

$\ddagger$ Nacalai Tesque, Tokyo, Japan.

$\S$ Wako Pure Chemical, Osaka, Japan.
(Nembutal; Abbott, North Chicago, IL, USA), after which blood was withdrawn by cardiac puncture with a heparinized syringe. Immediately after killing, the liver was weighed and two portions were removed: one from the left lateral lobe and the other from the largest lobe. The samples were weighed separately and stored frozen $\left(-80^{\circ} \mathrm{C}\right)$ until lipid extraction. Plasma was prepared from blood and stored frozen $\left(-80^{\circ} \mathrm{C}\right)$ until analysis. Faeces that had been collected in a $24 \mathrm{~h}$ period in the last week of feeding were also stored frozen $\left(-80^{\circ} \mathrm{C}\right)$ until analysis. All experiments were conducted in accordance with the guidelines on the care of experimental animals as approved by the Animal Research Committee at Tottori University.

\section{Lipid analyses}

Plasma total cholesterol, HDL-cholesterol, non-esterified cholesterol, NEFA and triacylglycerol were determined by Cholesterol C-Test Wako, HDL-Cholesterol-Test Wako, Free-Cholesterol E-Test Wako, NEFA C-Test Wako and Triacylglycerol E-Test Wako kits (Wako Pure Chemical) respectively. Total lipids in the liver were extracted by the procedure of Folch et al. (1957). The extracts dissolved in $\mathrm{CHCl}_{3}$ were diluted with Triton X100 (100 g/l) 2-propanol, followed by measurement of triacylglycerol and cholesterol contents using Triacylglycerol E-Test Wako and Cholesterol C-Test Wako kits (Wako Pure Chemical) respectively. Hepatic lipids were expressed on the basis of fresh liver weight.

\section{Total bile acids in bile and faeces}

Bile was collected by gall bladder puncture with a syringe. Faeces bile acids and cholesterol were extracted with chloroform-methanol $(2: 1, \mathrm{v} / \mathrm{v})$. Total cholesterol in faeces and total bile acids in bile and faeces were determined by cholesterol C-Test Wako and Total Bile AcidsTest Wako kits (Wako Pure Chemical).

\section{Lymphatic absorption of triacylglycerol}

Rats were used for this experiment. The control group was fed a commercial diet powder (CE-2; Nihon CLEA) and the treated group the commercial diet powder supplemented with bLF $(10 \mathrm{~g} / \mathrm{kg})$. Each group was fed the diet for 4 weeks; the animals were then used for the experiment. The intestinal lymph duct was cannulated according to the method of Bollman et al. (1948) under pentobarbital sodium anaesthesia. Postoperatively, the rats were warmed up by using a heating pad. The test meal containing $100 \mathrm{~g}$ lard/l saline $(9 \mathrm{~g} \mathrm{NaCl} / \mathrm{l})$ was infused into the duodenum by using a twenty-six-gauge needle over $1 \mathrm{~min}$ at a dose of $3 \mathrm{ml} / \mathrm{kg}$ body weight. Lymph fluid was collected each hour into a plastic tube under the anaesthesia up to $6 \mathrm{~h}$. The volume of lymph fluid was measured and stored frozen $\left(-80^{\circ} \mathrm{C}\right)$ until lipid analysis. The triacylglycerol concentration in lymph fluid was determined by Triacylglycerol E-Test Wako kits (Wako Pure Chemical). Finally, the total output of triacylglycerol into lymph fluid was calculated for each sample. 


\section{Statistical analyses}

The results are expressed as means values with their standard errors. The significance of differences between the groups was determined by the Student's $t$ test in Expt 1 and two-way ANOVA (diet $\times$ treatment) followed by post hoc test in Expt 2. A probability level of $P<0.05$ was taken to be statistically significant.

\section{Results}

Expt 1: effects of bovine lactoferrin in mice fed the standard diet

During the early stage of the experiment, the bLF-treated group gained slightly more weight than the control group. Final body weight, however, was almost the same in both groups, and ANOVA revealed no significant differences between the two groups. Diet intake in bLF-treated group was similar to that in the control.

It is apparent that bLF treatment affects lipid concentrations in plasma. The plasma total and non-esterified cholesterol tended to increase at 115.7 and $116.1 \%$ in the bLF-treated group compared with the control value; the difference between the two diet groups was not significant (Fig. 1(A)). bLF treatment increased the plasma concentration of HDL cholesterol significantly (+24.8\%, $P<0 \cdot 01)$ over the control value. The HDL-cholesterol:total cholesterol ratio was 0.76 (SEM0.02) in the control and 0.82 (SEM 0.01) in the bLF-diet group, with a significant difference $(P<0 \cdot 05)$. Treatment with bLF significantly reduced

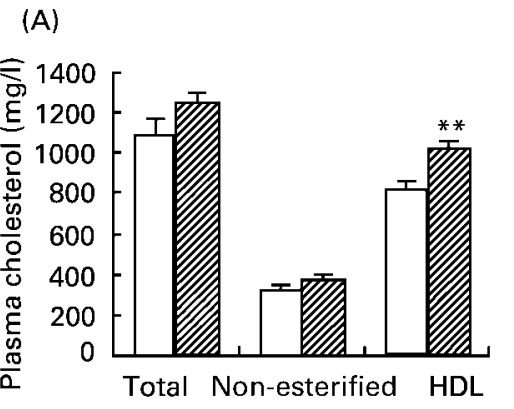

(B)
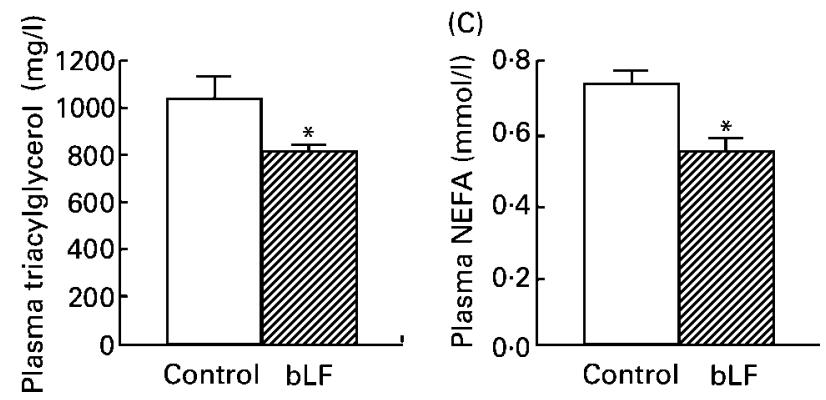

Fig. 1. Effect of bovine lactoferrin (bLF) treatment on plasma lipids level in mice fed a standard diet. Concentrations of cholesterol ((A), total, non-esterified and HDL), triacylglycerol (B) and NEFA (C) in plasma are shown for the control group $(\square)$ and bLF-treated group $(10 \mathrm{~g} / \mathrm{kg}$ diet; $\mathbb{Z})$. For details of diets and procedures, see Table 1 and p. 000. Values are means with their standard errors shown by vertical bars (seven mice per group). Mean values were significantly different from those of the control group: ${ }^{\star} P<0.05$, ${ }^{\star *} P<0.01$. the plasma concentrations of triacylglycerol (Fig. 1(B)) and NEFA (Fig. 1(C)) to levels 78.6 and $72.6 \%$ below the control values $(P<0.05)$ respectively.

The bLF treatment decreased the hepatic lipid levels in mice. The treatment reduced total hepatic cholesterol and triacylglycerol to $67(P<0.01$, Fig. 2(A)) and 58 $(P<0.05$, Fig. 2(B)) \% of the control values respectively. The changes in hepatic lipids were accompanied by a tendency for a decrease in liver weight (to $92.9 \%$ of the control value, NS).

\section{Expt 2: effects of bovine lactoferrin in mice fed the high-fat diet}

The body-weight gains differed between groups during the study. The greatest gain in body weight was noted in the HF group in the second week. Diet intake in HF group was about $50 \%$ that of the basal-diet group, and the treatment with bLF did not have any effect on the diet intake.

The HF diet significantly increased the lipid contents in both plasma and liver in comparison with the standard commercial diet in the Expt 1. Both of the groups that were fed a HF diet had significant elevations in plasma and liver cholesterol concentrations, as expected. The HF diet significantly increased $(P<0 \cdot 05)$ the plasma non-esterified cholesterol concentration to 767 (SEM 56) $\mathrm{mg} / \mathrm{l}$ (Table 2). The addition of bLF to the HF diet did not

(A)

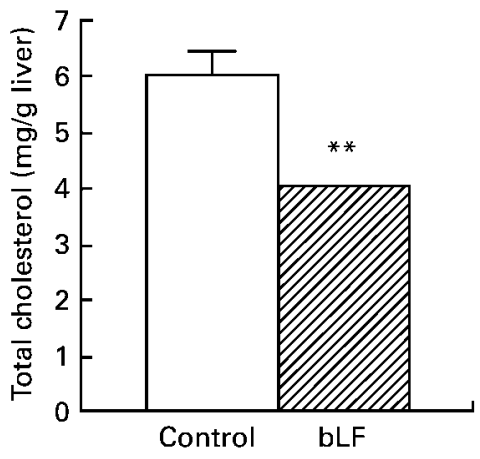

(B)

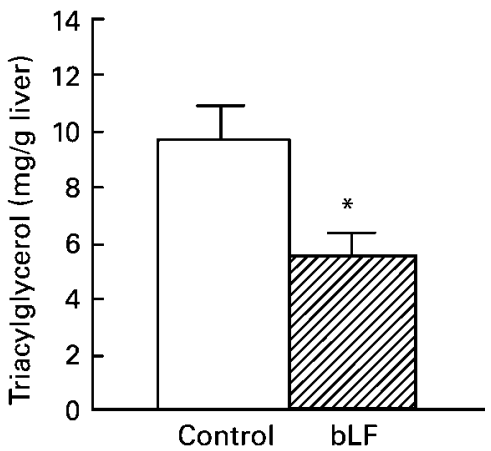

Fig. 2. Effect of bovine lactoferrin (bLF) treatment on the liver lipid concentrations in mice fed a standard diet. Total cholesterol (A) and triacylglycerol $(B)$ concentrations in liver are shown in control group $(\square)$ and bLF-treated group (10 g/kg diet; 泩). For details of diets and procedures, see Table 1 and p. 000 . Values are means with their standard errors shown by vertical bars (seven mice per group). Mean values were significantly different from those of the control group: ${ }^{*} P<0.05,{ }^{* *} P<0.01$. 
Table 2. Influence of bovine lactoferrin treatment on the plasma lipids of mice fed a high-fat diet ${ }^{\star}$ (Mean values with their standard errors for seven mice per group)

\begin{tabular}{|c|c|c|c|c|c|c|c|c|c|c|}
\hline \multirow[b]{2}{*}{ Diet } & \multicolumn{2}{|c|}{$\begin{array}{l}\text { Total cholesterol } \\
(\mathrm{mg} / \mathrm{l})\end{array}$} & \multicolumn{2}{|c|}{$\begin{array}{l}\text { Non-esterified } \\
\text { cholesterol (mg/l) }\end{array}$} & \multicolumn{2}{|c|}{$\begin{array}{l}\text { HDL-cholesterol } \\
\text { (mg/l) }\end{array}$} & \multicolumn{2}{|c|}{$\begin{array}{l}\text { Triacylglycerol } \\
(\mathrm{mg} / \mathrm{l})\end{array}$} & \multicolumn{2}{|c|}{$\begin{array}{c}\text { NEFA } \\
(\mathrm{mmol} / \mathrm{l})\end{array}$} \\
\hline & Mean & SEM & Mean & SEM & Mean & SEM & Mean & SEM & Mean & SEM \\
\hline Basal & 2112 & 299 & 515 & 53 & 870 & 139 & 448 & 56 & & \\
\hline Basal + bLF & 2199 & 188 & 521 & 42 & 866 & 89 & 374 & 93 & & \\
\hline $\mathrm{HF}$ & 2122 & 143 & 767 & 56 & 1155 & 74 & 320 & 74 & & \\
\hline $\mathrm{HF}+\mathrm{bLF}$ & 1898 & 156 & 572 & 71 & 1008 & 24 & 364 & 63 & & \\
\hline \multicolumn{11}{|c|}{ Statistical significance of effect (two-way ANOVA) } \\
\hline Fat amount & \multicolumn{2}{|c|}{ NS } & \multicolumn{2}{|c|}{$P<0.05$} & \multicolumn{2}{|c|}{ NS } & \multicolumn{2}{|c|}{ NS } & \multicolumn{2}{|c|}{$P<0.05$} \\
\hline bLF treatment & \multicolumn{2}{|c|}{ NS } & \multicolumn{2}{|c|}{ NS } & \multicolumn{2}{|c|}{ NS } & \multirow{2}{*}{\multicolumn{2}{|c|}{$\begin{array}{l}\text { NS } \\
\text { NS }\end{array}$}} & \multirow{2}{*}{\multicolumn{2}{|c|}{$\begin{array}{l}\text { NS } \\
\text { NS }\end{array}$}} \\
\hline Interaction & \multicolumn{2}{|c|}{ NS } & \multicolumn{2}{|c|}{ NS } & \multicolumn{2}{|c|}{ NS } & & & & \\
\hline
\end{tabular}

* For details of diets and procedures, see Table 1 and p. 534.

cause a significant difference by bLF treatment or interaction of fat level $\times$ bLF treatment. bLF had no clear effect on plasma HDL-cholesterol in the HF group. The HF diet significantly reduced $(P<0.05)$ the plasma NEFA below the level found in the mice fed the basal diet. For the basal-diet mice and the HF-diet mice, bLF had no effect on the NEFA level.

The hepatic total cholesterol was approximately twice as high in the HF diet group as in the basal diet group (Table 3). In mice fed the HF diet, bLF did not cause significant difference by treatment. Hepatic triacylglycerol had a similar tendency: triacylglycerol content in the $\mathrm{HF}$ diet group increased to $162.3 \%$ that of the basal diet group, and bLF treatment did not suppress the increment (Table 3).

To evaluate the effects of bLF on bile acid secretion and enterohepatic circulation of bile acid, we estimated total bile acids in bile and faeces. The totals are shown in Table 4. There were no significant differences in the total bile acid in bile amongst the basal, HF and HF + bLF groups. However, total bile acid excreted in the faeces was significantly increased $(P<0.01)$ by feeding the HF diet. bLF did not have a significant effect on the total bile acids in the faeces compared with the HF-diet group. There were no significant differences in the total faecal cholesterol.

Table 3. Influence of bovine lactoferrin treatment on the liver lipids of mice fed a high-fat diet*

(Mean values with their standard errors for seven mice per group)

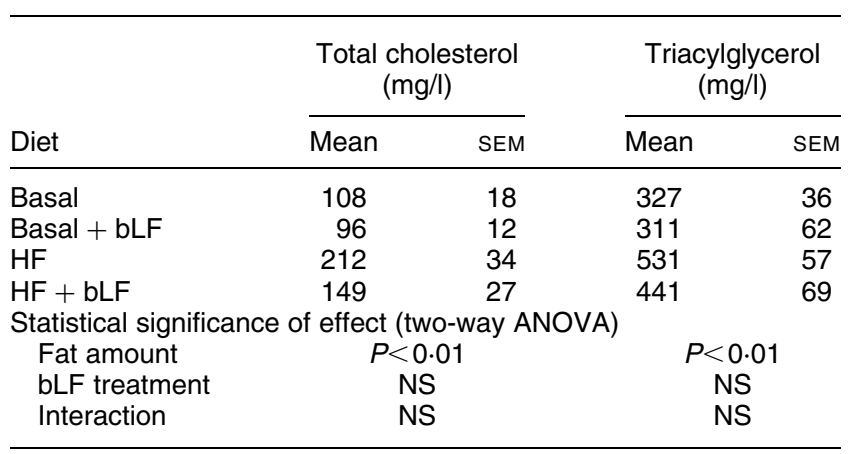

bLF, bovine lactoferrin.

${ }^{*}$ For details of diets and procedures, see Table 1 and p. 534.

\section{Lymphatic absorption of triacylglycerol in rats}

Fig. 3 shows the lymphatic triacylglycerol output during the first $6 \mathrm{~h}$ after the duodenal infusion of $100 \mathrm{~g}$ lard/l saline $(9 \mathrm{~g} \mathrm{NaCl} / \mathrm{l})$ solution. The fasting lymphatic triacylglycerol output was about $5 \mathrm{~g} / \mathrm{l}$ and $5 \mathrm{mg} / \mathrm{h}$ per $\mathrm{kg}$ body weight in both groups. There was a marked change in the lymphatic triacylglycerol concentration following the infusion of lard. The concentration of lymphatic triacylglycerol in the control group increased rapidly and was maintained at a higher concentration throughout the experimental period. In contrast, the concentration of lymphatic triacylglycerol in the bLF-group was significantly lower than that in the control $(P<0.0001)$. Total lymphatic triacylglycerol output in the bLF-treated group was also significantly lower during the first $2 \mathrm{~h}$ compared with the control value $(P<0 \cdot 0001)$.

\section{Discussion}

The present study is the first to demonstrate that milkderived lactoferrin reduces plasma or hepatic cholesterol and triacylglycerol concentrations, with an increase in plasma HDL-cholesterol, an anti-atherogenic lipoprotein, in mice fed standard diets. These effects of bLF may serve to prevent atherosclerosis, since epidemiological studies indicate an inverse correlation between HDLcholesterol levels and the incidence of CHD (Jeppesen et al. 1998). However, bLF had no significant suppressive effects on the lipid metabolism in the mice fed a HF diet. In the Expt 2, the HF diet contained $10 \mathrm{~g}$ cholesterol and $2.5 \mathrm{~g}$ bile powder $/ \mathrm{kg}$. bLF could not suppress the elevation of cholesterol and triacylglycerol concentrations in plasma or liver. bLF may affect on the plasma and liver lipid concentrations when a standard diet is fed.

It has been reported that lactoferrin interferes with ligand binding to lipoprotein receptor protein (LRP) and inhibits selective uptake of HDL-cholesteryl esters by $35-50 \%$ in human primary adipocytes and SW872 liposarcoma cells (Vassiliou et al. 2001). LRP may contribute physiologically to HDL-cholesteryl ester-selective uptake in adipocytes, because lactoferrin is another LRP ligand that is also a potent inhibitor of ApoE and an inhibitor of lipoprotein lipase binding to LRP (Willnow et al. 1992). Kajikawa et al. (1994) reported that bLF reduced the 
Table 4. Influence of bovine lactoferrin on concentrations of total bile acids and cholesterol in bile and faeces of mice fed a high-fat diet* (Mean values and standard errors for seven mice per group)

\begin{tabular}{|c|c|c|c|c|c|c|}
\hline \multirow[b]{3}{*}{ Diet } & \multirow{2}{*}{\multicolumn{2}{|c|}{$\frac{\text { Bile }}{\text { Bile acid }(\mathrm{nmol} / \mathrm{g})}$}} & \multicolumn{4}{|c|}{ Faeces } \\
\hline & & & \multicolumn{2}{|c|}{ Bile acid $(\mathrm{nmol} / \mathrm{g})$} & \multicolumn{2}{|c|}{ Cholesterol $(\mathrm{mg} / \mathrm{g})$} \\
\hline & Mean & SEM & Mean & SEM & Mean & SEM \\
\hline Basal & 114.7 & 11.5 & $798 \cdot 1$ & $105 \cdot 3$ & $13 \cdot 3$ & 3.9 \\
\hline Basal + bLF & 118.5 & $10 \cdot 2$ & $820 \cdot 3$ & 111.5 & 13.9 & $2 \cdot 9$ \\
\hline $\mathrm{HF}$ & 121.3 & 13.2 & 1138.9 & $160 \cdot 4$ & 14.8 & 2.0 \\
\hline $\mathrm{HF}+\mathrm{bLF}$ & $124 \cdot 2$ & $19 \cdot 1$ & $1465 \cdot 7$ & 155.5 & $15 \cdot 8$ & 1.4 \\
\hline \multicolumn{7}{|l|}{ Statistical significance of effect (two-way ANOVA) } \\
\hline Fat amount & \multirow{2}{*}{\multicolumn{2}{|c|}{ NS }} & \multicolumn{2}{|c|}{$P<0.01$} & \multicolumn{2}{|c|}{ NS } \\
\hline bLF treatment & & & \multirow{2}{*}{\multicolumn{2}{|c|}{ NS }} & \multirow{2}{*}{\multicolumn{2}{|c|}{ NS }} \\
\hline Interaction & \multicolumn{2}{|c|}{$\begin{array}{l}\text { NS } \\
\text { NS }\end{array}$} & & & & \\
\hline
\end{tabular}

bLF, bovine lactoferrin; HF, high fat.

${ }^{*}$ For details of diets and procedures, see Table 1 and p. 534.

(A)

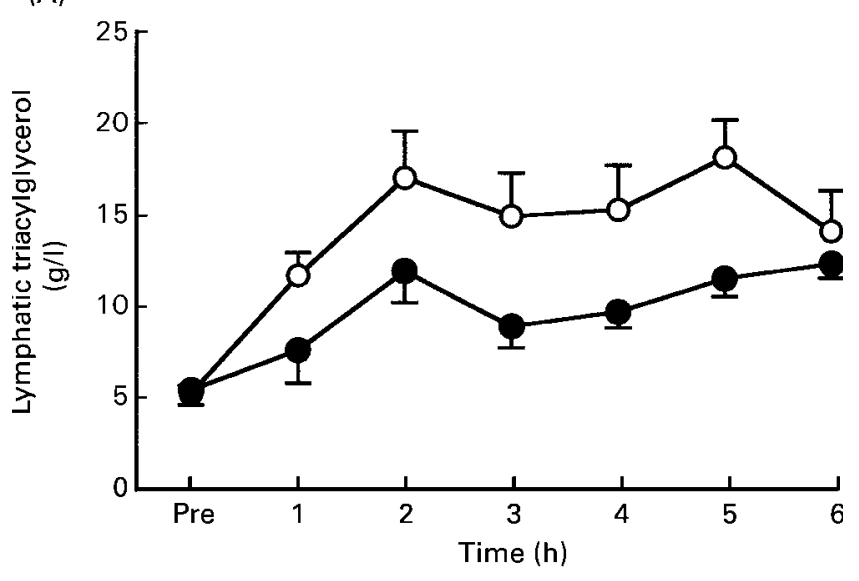

(B)

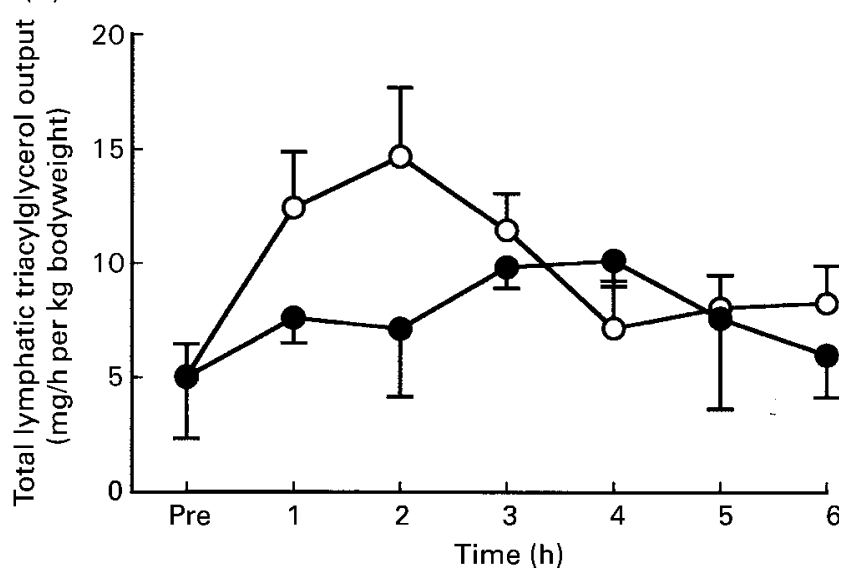

Fig. 3. Effect of bovine lactoferrin (bLF) treatment on the lymphatic absorption of triacylglycerol in rats fed a standard diet. Concentrations of lymphatic triacylglycerol $(A)$ and total lymphatic triacylglycerol output (B) are shown for the control group (O) and bLF-treated group $(10 \mathrm{~g} / \mathrm{kg}$ diet; $\bullet)$. Values are means with their standard errors shown by vertical bars (four to six rats per group)

accumulation of cholesteryl esters in macrophages incubated with acetylated LDL by more than $80 \%$ compared with the control value. In addition, van Dijk et al. (1991) reported that lactoferrin inhibits the uptake of chylomicrons into liver in vivo, whereas the liver uptake of $\beta$-VLDL is efficiently blocked. Thus, it is probable that bLF modifies lipid metabolism in liver and helps to reduce the accumulation of lipids into the adipose tissue and liver.

To clarify whether bLF affects the production of bile acids and/or re-absorption of bile acids from intestine, we measured total concentrations of bile acids in bile and faeces. bLF did not have significant effects on the excretion of bile acids in faeces, although the mice fed the $\mathrm{HF}$ diet excreted significantly greater quantities of total bile acids in faeces relative to the mice fed the basal diet. These results suggest that bLF does not affect the re-uptake of bile acids in intestine. The liver plays the central role in maintaining whole-body lipid and lipoprotein balance. In the steady state, the faecal sterol loss must be equalled by the rate of intestinal cholesterol absorption and hepatic cholesterol synthesis. On the other hand, van Dijk et al. (1993) reported that when $\left[{ }^{3} \mathrm{H}\right]$ cholesteryl (ester)-labelled chylomicrons were injected into rats, lactoferrin not only delayed the rate at which radioactivity was excreted into the bile, but also reduced the total amount of radioactivity recovered therein. Apparently, hepatic uptake of chylomicron cholesteryl (esters) must be efficient in order to efficiently remove and secrete this cholesterol into bile that protects from extrahepatic deposits. Furthermore, in another study lactoferrin reduced the biliary secretion of radioactivity, especially during the first hour after injection (van Dijk et al. 1993). Taken together, bLF may affect on the hepatic cholesterol uptake in our present study.

It is well known that bLF is one of the most potent basic proteins and its surface is covered with a positive charge. The strongly basic protein lactoferrin inhibited the rat liver's uptake of chylomicron remnants (Huettinger et al. 1988). Parenchymal cells of the liver probably represent the chylomicron remnant receptor (van Dijk et al. 1993), as human lactoferrin inhibited the rat liver's uptake of $\beta$-VLDL containing chylomicron remnants (Murase et al. 2001); however, a negatively charged heparin molecule accelerates the clearance of chylomicrons by promoting lipoprotein lipase-mediated hydrolysis of triacylglycerols (Redgrave \& Callow, 1990). Thus, bLF is unlikely to 
accelerate the clearance of lipids from plasma, at least via the uptake of chylomicron remnants in liver.

We tried to estimate the possibility that bLF directly suppresses the intestinal absorption of lipids. Interestingly, the concentration of lymphatic triacylglycerol was significantly suppressed by chronic treatment with bLF in rats (Fig. 3). Thus, it is probable that bLF has a suppressive effect on the lipid absorption in mice. These results may explain the lower concentrations of plasma NEFA and triacylglycerol in mice fed a standard diet. Recently, Nagaoka et al. (2001) reported a novel hypocholesterolaemic peptide derived from $\beta$-lactoglobulin tryptic hydrolysate. They suggested that the inhibition of micellar solubility of cholesterol suppresses the absorption of cholesterol by a direct interaction between cholesterolmixed micelles. Thus, bLF may affect on the micellar solubility of cholesterol, because bLF apparently suppressed lymphatic triacylglycerol absorption in our present study. Further study is necessary to clarify a precise mechanism for suppressive effect of bLF on the lipid metabolism.

In conclusion, treatment with bLF in mice had a beneficial effect on plasma cholesterol levels and retarded hepatic lipid accumulation. bLF had a suppressive effect on the lymphatic triacylglycerol absorption in rodents. As a natural substance, bLF may be thus be useful in the control of lipid accumulation.

\section{Acknowledgement}

This investigation was supported by a Grant-in-Aid for Scientific Research from the Ministry of Education, Science, Sports and Culture of Japan (no. 14360179).

\section{References}

Bennett RM \& Davis J (1981) Lactoferrin binding to human peripheral blood cells: an interaction with a ßenriched population of lymphocytes and a subpopulation of adherent mononuclear cells. J Immunol 127, 1211-1216.

Bollman JL, Cain JC \& Grindlay JH (1948) Techniques for the collection of lymph from the liver, small intestine or thoracic duct of the rat. J Lab Clin Med 33, 1349-1352.

Brock JH (2002) The physiology of lactoferrin. Biochem Cell Biol 80, 1-6.

Crawford SE \& Borensztajn J (1999) Plasma clearance and liver uptake of chylomicron remnants generated by hepatic lipase lipolysis: evidence for a lactoferrin-sensitive and apolipoprotein E-independent pathway. J Lipid Res 40, 797-805.

Debanne MT, Regoeczi E, Sweeney GD \& Krestynski F (1985) Interaction of human lactoferrin with the rat liver. Am J Physiol 248, G463-G469.

van Dijk MCM, Pieters M \& van Berkel TJC (1993) Kinetics of biliary secretion of chylomicron remnant cholesterol (esters) in the rat. Eur J Biochem 211, 781-787.

van Dijk MCM, Ziere GJ, Boers W, Linthorst C, Bijsterbosch MK \& van Berkel TJC (1991) Recognition of chylomicron remnants and $\beta$-migrating very low-density lipoproteins by the remnant receptor of parenchymal liver cells is distinct from the liver $\alpha 2$-macroglobulin recognition site. Biochem $J$ 279, $863-870$.

Fillebeen C, Descamps L, Dehouck MP, Fenart L, Benaissa M, Spik G, Cecchelli R \& Pierce A (1999) Receptor-mediated transcytosis of lactoferrin through the blood brain barrier. $J$ Biol Chem 274, 11229-11235.

Folch J, Lees M \& Sloane-Stanley GHA (1957) A simple method for the isolation and purification of total lipides from animal tissue. J Biol Chem 226, 497-509.

Gijsbertus JZ, van Dijk MCM, Martin KB \& van Berkel TJC (1999) Lactoferrin uptake by the rat liver. J Biol Chem 267, 7011-7017.

Hayashida K, Takeuchi T, Shimizu H, Ando K \& Harada E (2003) Novel function of bovine milk-derived lactoferrin on antinociception mediated by $\mu$-opioid receptor in the rat spinal cord. Brain Res 965, 239-245.

Hokanson JE \& Austin MA (1996) Plasma triglyceride level is a risk factor for cardiovascular disease independent of high-density lipoprotien cholesterol level: a meta-analysis of population-based prospective studies. $J$ Cardiovasc Risk 3, 213-219.

Huettinger M, Retzek H, Eder M \& Goldenberg H (1988) Characteristics of chylomicron remnant uptake into rat liver. Clin Biochem 21, 87-92.

Jeppesen J, Hein HO, Suadicani P \& Gyntelberg F (1998) Triglyceride concentration and ischemic heart disease: an eight-year follow-up in the Cophenhagen Male Study. Circulation 97, $1029-1036$

Kajikawa M, Ohta T, Takase M, Kawase K, Shimamura S \& Matsuda I (1994) Lactoferrin inhibits cholesterol accumulation in macrophages mediated by acetylated or oxidized low-density lipoproteins. Biochim Biophys Acta 1213, 82-90.

Kohashi M, Takahashi A \& Iwai K (1990) Effect of a histidineexcess diet on a tetra-hydrofolylpolyglutamate pattern in rat liver. J Nutr Sci Vitaminol 36, 11-19.

Masson PL, Hermans JF \& Dive C (1996) An iron-binding protein common to many external secretions. Clin Chim Acta 14, 735-739.

Murase T, Kondo H, Hase T, Tokimitsu I \& Saito M (2001) Abundant expression of uncoupling protein-2 in the small intestine: up-regulation by dietary fish oil and fibrates. Biochim Biophys Acta 1530, 15-22.

Nagaoka S, Futamura Y, Miwa K, Awano T, Yamauchi K, Kanamatu Y, Kojima T \& Kuwata T (2001) Identification of novel hypocholesterolemic peptides derived from bovine milk beta-lactoglobulin. Biochem Biophys Res Commun 281, $11-17$.

Redgrave TG \& Callow MJ (1990) The effect of insulin deficiency on the metabolism of lipid emulsion models of triacylglycerol-rich lipoproteins in rats. Metabolism 39, 1-10.

van Snick JL \& Masson PL (1976) The binding of human lactoferrin to mouse peritoneal cells. J Exp Med 144, 1568-1580.

Vassiliou G, Benoist F, Lau P, Kavaslar GN \& McPherson R (2001) The low density lipoprotein receptor-related protein contributes to selective uptake of high density lipoprotein cholesteryl esters by SW872 liposarcoma cells and primary human adipocytes. J Biol Chem 276, 48823-48830.

Willnow TE, Goldstein JL, Orth K, Brown JS \& Herz J (1992) Low density lipoprotein receptor-related protein and gp330 bind similar ligands, including plasminogen activator-inhibitor complexes and lactoferrin, an inhibitor of chylomicron remnant clearance. J Biol Chem 267, 26172-26180.

Zhang X \& Beynen AC (1993) Lowering effect of dietary milkwhey protein $v$. casein on plasma and liver cholesterol concentrations in rats. Br J Nutr 70, 139-146.

Ziere GJ, van Dijk MCM, Bijsterbosch MK \& van Berkel TJC (1992) Lactoferrin uptake by the rat liver. Characterization of the recognition site and effect of selective modification of arginine residues. $J$ Biol Chem 267, 11229-11235. 